Article

\title{
Toxocara canis- and Toxocara cati-Induced Neurotoxocarosis Is Associated with Comprehensive Brain Transcriptomic Alterations
}

\author{
Patrick Waindok ${ }^{1}$, Elisabeth Janecek-Erfurth ${ }^{1,+}{ }^{+}$, Dimitri L. Lindenwald ${ }^{1}$ D, Esther Wilk ${ }^{2}$, Klaus Schughart $^{2,3,4}{ }^{(D,}$, \\ Robert Geffers ${ }^{5}$ id and Christina Strube ${ }^{1, *(D)}$
}

1 Institute for Parasitology, Centre for Infection Medicine, University of Veterinary Medicine Hannover, 30559 Hanover, Germany; patrick.waindok@freenet.de (P.W.); Elisabeth.Janecek@gmx.de (E.J.-E.); dimitril@gmx.net (D.L.L.)

2 Department of Infection Genetics, Helmholtz Centre for Infection Research, 38124 Braunschweig, Germany; Wilk@rochusmummert.com (E.W.); Klaus.Schughart@helmholtz-hzi.de (K.S.)

3 Department of Microbiology, Immunology and Biochemistry, University of Tennessee Health Science Centre, Memphis, TN 38163, USA

4 Institute for Animal Breeding and Genetics, University of Veterinary Medicine Hannover, 30559 Hanover, Germany

5 Research Group Genome Analytics, Helmholtz Centre for Infection Research, 38124 Braunschweig, Germany; robert.geffers@helmholtz-hzi.de

* Correspondence: christina.strube@tiho-hannover.de; Tel.: +49-511-953-8711

+ Present address: Centre for Experimental and Clinical Infection Research TWINCORE, a Joint Venture between the Hanover Medical School and the Helmholtz Centre for Infection Research, Institute for Experimental Infection Research, 30625 Hanover, Germany.

check for

updates

Citation: Waindok, P.;

Janecek-Erfurth, E.; Lindenwald, D.L.; Wilk, E.; Schughart, K.; Geffers, R.; Strube, C. Toxocara canis- and Toxocara cati-Induced

Neurotoxocarosis Is Associated with Comprehensive Brain Transcriptomic Alterations. Microorganisms 2022, 10, 177. https://doi.org/10.3390/ microorganisms10010177

Academic Editor: Ali Rostami

Received: 16 December 2021

Accepted: 11 January 2022

Published: 14 January 2022

Publisher's Note: MDPI stays neutral with regard to jurisdictional claims in published maps and institutional affiliations.

Copyright: (C) 2022 by the authors. Licensee MDPI, Basel, Switzerland. This article is an open access article distributed under the terms and conditions of the Creative Commons Attribution (CC BY) license (https:// creativecommons.org/licenses/by/ $4.0 /)$.

\begin{abstract}
Toxocara canis and Toxocara cati are globally occurring zoonotic roundworms of dogs and cats. Migration and persistence of Toxocara larvae in the central nervous system of paratenic hosts including humans may cause clinical signs of neurotoxocarosis (NT). As pathomechanisms of NT and host responses against Toxocara larvae are mostly unknown, whole-genome microarray transcription analysis was performed in cerebra and cerebella of experimentally infected C57Bl/6J mice as paratenic host model at days $14,28,70,98$, and 120 post-infection. Neuroinvasion of T. cati evoked 220 cerebral and 215 cerebellar differentially transcribed genes (DTGs), but no particular PANTHER (Protein ANalysis THrough Evolutionary Relationships) pathway was affected. In T. canis-infected mice, 1039 cerebral and 2073 cerebellar DTGs were identified. Statistically significant dysregulations occurred in various pathways, including cholesterol biosynthesis, apoptosis signaling, and the Slit/Robo mediated axon guidance as well as different pathways associated with the immune and defense response. Observed dysregulations of the cholesterol biosynthesis, as well as the Alzheimer disease-amyloid secretase pathway in conjunction with previous histopathological neurodegenerative findings, may promote the discussion of T. canis as a causative agent for dementia and/or Alzheimer's disease. Furthermore, results contribute to a deeper understanding of the largely unknown pathogenesis and host-parasite interactions during NT, and may provide the basis for prospective investigations evaluating pathogenic mechanisms or designing novel diagnostic and therapeutic approaches.
\end{abstract}

Keywords: neural larva migrans; toxocarosis; toxocariasis; gene transcription analysis; differential transcription; cholesterol biosynthesis; neurodegeneration; Alzheimer's disease; microarray

\section{Introduction}

The dog and cat roundworm Toxocara canis and Toxocara cati are globally occurring intestinal parasites with canids and felids as definitive hosts. Due to the transpacental and/or lactogenic transmission to the offspring, they are of particular veterinary importance. Infections in dogs and cats have been associated with a variety of pathologies, 
induced either by the tracheal or somatic migration of larvae or adult nematodes in the gastrointestinal tract [1]. The global pooled prevalence of Toxocara infection in dogs is estimated at $11.1 \%$ and in cats at $17.0 \%$ [2,3], with significantly higher prevalences in young, rural, or stray animals. An estimated $\geq 100$ million dogs and cats are infected and contaminate the environment with roundworm eggs [2,3]. Besides definitive hosts, a broad range of animals including humans can act as paratenic hosts after accidental ingestion of embryonated third-stage larvae (L3) containing eggs or L3 in tissues.

Toxocarosis is one of the most frequently occurring zoonotic helminthoses worldwide [4], with an estimated global seroprevalence rate of 19\% [5]. As in other paratenic hosts, human Toxocara infection is characterized by migration and persistence of L3 in paratenic host tissues. Clinical outcome and severity of toxocarosis depend on the intensity of infection, the duration and distribution of larval migration as well as occurring symptoms [6]. Accumulation and persistence of Toxocara-larvae in the central nervous system (CNS) may induce a syndrome called neurotoxocarosis (NT) $[7,8]$. However, the complex pathogenesis of NT results in a challenging diagnosis, wherefore the prevalence of NT is probably underestimated $[9,10]$. Common clinical findings are mostly non-specific, comprising encephalitis, myelitis, cerebral vasculitis, and eosinophilic meningoencephalitis, but NT has also been implicated to induce various neuropsychological disorders as well as neurological and cognitive deficits [7,8,11-14]. Toxocara canis is considered the causative agent of most human NT cases, wherefore the majority of experimental NT studies in rodents as model organisms have focused on this species [15]. Nevertheless, neuroinvasion of $T$. cati larvae also induces NT, but has only been marginally studied to date [15-18].

Most knowledge on NT is derived from only a small number of clinical cases or correlations of neurological disorders with Toxocara-seropositivity in humans [8] and a few studies only investigating molecular pathogenic mechanisms in laboratory animal models [15]. The progression of the disease in T. canis-infected mice is characterized by demyelination, focal malacia, mixed-cell infiltration as well as congestion, and neuronal necrosis $[19,20]$. At the molecular level, NT alters the transcription and expression patterns of different myelin marker genes [21]. Furthermore, neuroinvasion of Toxocara spp. impacts the complex molecular signaling network in infection and inflammation. For example, levels of anti-inflammatory immunoregulative molecules, including the cytokines interleukin IL-4 and IL-5 as well as regulatory lipid mediators such as neuroprotectin D1 are increased [22,23]. Furthermore, the ratio of anti-inflammatory 13- hydroxyoctadecadienoic acid (HODE) to pro-inflammatory 9-HODE is shifted in favor of 13-HODE [22]. Janecek et al. [24] identified a plethora of differentially transcribed genes (DTGs) in brains of T. canisand T. cati-infected C57BL/6J mice as paratenic host model at day 42 post-infection (pi), where DTGs were mainly associated with the host's immune response, especially the defense/inflammatory response and lipid/cholesterol biosynthetic processes. However, many questions regarding pathogenic mechanisms and immunogenic reactions during NT have not been clarified yet. Therefore, the aim of this study was to perform an extensive characterization of transcriptional changes during the course of neuroinfection. Such identification of key regulatory mechanisms is necessary for an enhanced understanding of the largely unknown pathogenesis and mechanisms of host-parasite interactions during T. canis- and T. cati-induced NT.

\section{Materials and Methods}

\subsection{Experimental Infection}

Experimental infection was performed as previously described [24]. Briefly, eggs of Toxocara canis (field isolate HannoverTcanis2008) and Toxocara cati (field isolate HannoverTcati2010) were collected from feces of experimentally infected dogs and cats, respectively, maintained at the Institute for Parasitology, University of Veterinary Medicine Hannover, Germany. Eggs were purified from the feces by a combined sedimentation-flotation technique and incubated at $25^{\circ} \mathrm{C}$ in tap water for about four weeks to allow for embryonation. Afterward, eggs were stored at $4{ }^{\circ} \mathrm{C}$ until infection. 
A total of 90 5-week-old male and female C57BL/6JRccHsd were purchased (Harlan Laboratories, Horst, the Netherlands) and acclimatized for a period of one week. Mice were housed in Makrolon cages in a 12/12 h dark/light cycle, receiving a standard rodent diet (Altromin 1324, Altromin, Lage, Germany) and water ad libitum. At the age of 6 weeks, mice were randomly allocated to the control and infection groups of 30 animals each. Animals of the T. canis- and T. cati-group were orally infected with 2000 embryonated T. canis or T. cati eggs, respectively, in a total volume of $0.5 \mathrm{~mL}$ tap water. The control group received the same volume of tap water only. On days 7, 14, 28, 70, 98, and 120 pi, every five mice of the T. canis- and T. cati-infection group, as well as the control group, were euthanized. Brains were carefully removed, divided into the right and left hemispheres, and hemispheres were separated into cerebrum and cerebellum. The cerebra and cerebella of the right hemispheres of were individually stored in RNAlater ${ }^{\mathrm{TM}}$ (Qiagen, Hilden, Germany) according to the manufacturer's instructions and frozen at $-80^{\circ} \mathrm{C}$ until further processing.

\subsection{RNA Isolation and Processing for Microarray Experiments}

RNA was isolated from approx. $100 \mathrm{mg}$ of each cerebrum and cerebellum and processed for microarray analysis as previously described [24] using the RNeasy ${ }^{\circledR}$ Lipid Tissue Mini kit (Qiagen, Hilden, Germany), including a DNase digestion step according to the manufacturer's instructions. The quality and integrity of the total RNA (28S/18S rRNA ratio and RNA integrity number, respectively) were controlled using the Agilent Technologies 2100 Bioanalyzer (Agilent Technologies, Waldbronn, Germany). For three samples per group, time point, and brain region were used for microarray experiments. Microarray analysis was conducted as described by Janecek et al. [24] by labeling $100 \mathrm{ng}$ of sample RNA with Cy3 according to the one-color Quick Amp Low Input Labeling protocol (Agilent Technologies, Waldbronn, Germany). Labeled cRNA was hybridized to Agilent's $4 \times 44 \mathrm{k}$ Mouse V2 (Agilent Technologies, Waldbronn, Germany), Design ID: 026655 for $17 \mathrm{~h}$ at $65^{\circ} \mathrm{C}$ and scanned as described by Pommerenke et al. [25].

\subsection{Low-Level Analyses}

Initial processing of microarray data included background subtraction as well as data normalization using R (v.3.1.2, R Foundation for Statistical Computing, Vienna, Austria [26]) with the packages "limma" (Linear Models for Microarray and RNA-Seq Data) and "sva" (Surrogate Variable Analysis). The supervised sva (ssva) approach included in the "sva" package was conducted to adjust batch effects, with integrated control probes selected as a reference. To determine inter- and intra-group-specific variations and to confirm biological reproducibility, principal component analysis (PCA) was applied using the R package "affycoretools".

\subsection{Identification of Differentially Transcribed Microarray Probes and Corresponding Genes}

Differentially transcribed microarray probes (DTPs) were determined by SAM (Significance Analysis for Microarrays; R package "samr"), limma (Linear Models for Microarray and RNA-Seq Data; R package "limma"), and maSigPro (Microarray Significant Gene Expression Profiles; R package "maSigPro"). Selected criteria for each package were set as follows: SAM (del = 1.079 for cerebrum and del $=1.796$ for cerebellum to keep FDR computed by delta.table $<10 \%$, min. fold change $=0)$, limma ( $p=0.05$, adjustment by Benjamini-Hochberg, with weights by group), and maSigPro (step.method "backward", alfa $=0.05, \mathrm{rsq}=0.65$, vars $=$ "groups"). To reduce package-specific bias, solely probes and corresponding genes identified as differentially transcribed by all three methods were considered for the investigation. The intersection of package-derived DTPs was compared and visualized with Venny v.2.1 [27]. DTPs were assigned to corresponding differentially transcribed genes (DTGs) using R packages "annotate" and "MmAgilentDesign026655.db" v.3.2.2. 


\subsection{Pathway Analyses}

Association of identified DTGs with regulatory and metabolic pathways was conducted with the statistical overrepresentation test with Fisher's exact test and adjusted by the false discovery rate (FDR) correction provided by the Protein ANalysis THrough Evolutionary Relationships (PANTHER) database v.16.0 [28], using the PANTHER Pathways as annotation dataset for Mus musculus [29]. Pathways with an FDR-adjusted $p$-value $\leq 0.05$ were considered statistically significantly enriched.

\section{Results}

\subsection{Clinical Assessment}

Mice infected with either T. canis or T. cati showed reduced body weights compared to uninfected control mice. As previously observed by Janecek et al. [30], infected mice were exposed to varying degrees of clinical symptoms and neurobehavioral alterations. Alterations in both infection groups mainly started around day 6 pi with progressively increasing severity during the course of infection, although $T$. cati-induced neurotoxocarosis was generally characterized by less severe clinical signs and neurobehavioral alterations.

\subsection{Microarray Data}

The microarray data set is available at the NCBI's Gene Expression Omnibus (GEO) database under the accession number GSE190123.

\subsection{Principal Component Analysis}

Overall, PCA indicated differential gene transcriptions between Toxocara-infected and uninfected control mice as well as both brain areas. However, day 7 pi samples of T. canisand $T$. cati-infected mice showed considerable transcriptional divergences between each other and were therefore excluded from further analyses. As of day 14 pi, group data trended in a similar manner, especially in the T. canis infected mice, where PCA plots showed different clustering between cerebrum and cerebellum as well as a clear distinction to the uninfected control mice. Furthermore, samples from day 98 and day 120 pi of both brain parts clustered separately from the earlier study days (Figure 1). The T. cati-infected mice also showed distinct transcriptomic differences between the cerebrum and cerebellum, but sample clustering of the different time points was less pronounced (Figure 1). This was particularly true for the cerebellum, where no clear transcriptional differences could be observed compared to the uninfected control mice.

\subsection{Differentially Transcribed Microarray Probes and Corresponding Genes in Brains off T. canis-Infected Mice}

Transcriptional data analyses using $\mathrm{R}$ packages SAM, limma, and maSigPro revealed 1239 differentially transcribed microarray probes (DTPs) in the cerebrum during the course of $T$. canis infection. As 132 DTPs could not be annotated by the R package "annotate", and 68 probes were replicates for different genes, a total of 1039 differentially transcribed genes (DTGs) could be identified (Figure 2). Of these, 477 DTGs were upregulated and 289 were downregulated at each time point of the study. The remaining 273 DTGs did not show a consecutive trend and were either up- or downregulated at different time points of the analysis.

In the cerebellum, the infection with T. canis resulted in 2544 DTPs during the course of infection, corresponding to 2073 DTGs, as 304 probes could not be annotated and 167 probes were replicates of different genes. Of the total number of DTGs, 884 DTGs were upregulated and 599 were downregulated at each time point of the analysis. A varying dysregulation over the course of infection was observed for 590 DTGs. 

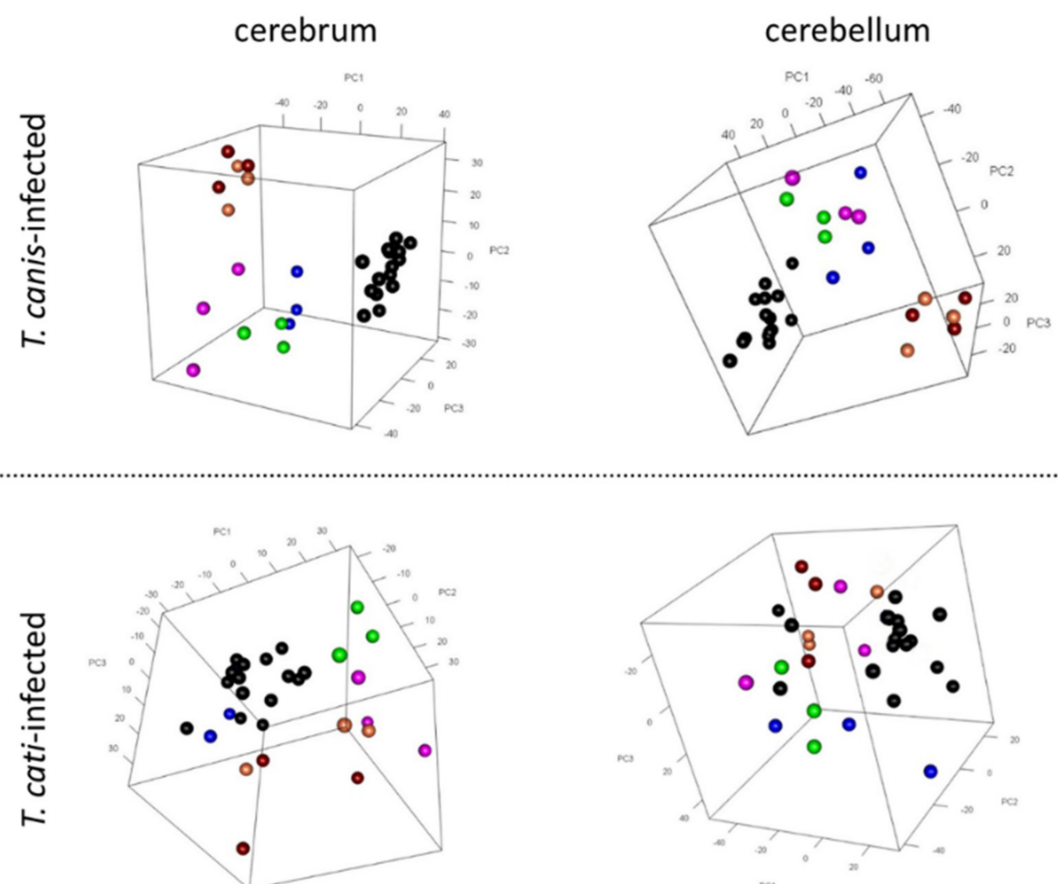

day 14 p.i.

day 28 p.i.

day 70 p.i.

day 98 p.i.

day 120 p.i.

- uninfected control

Figure 1. Principal component analysis of transcriptional changes in cerebra and cerebella of T. canisand T. cati-infected $\mathrm{C} 57 \mathrm{Bl} / 6 \mathrm{~J}$ mice at different time points post-infection. To provide a better overview, all respective control mice are shown in black.
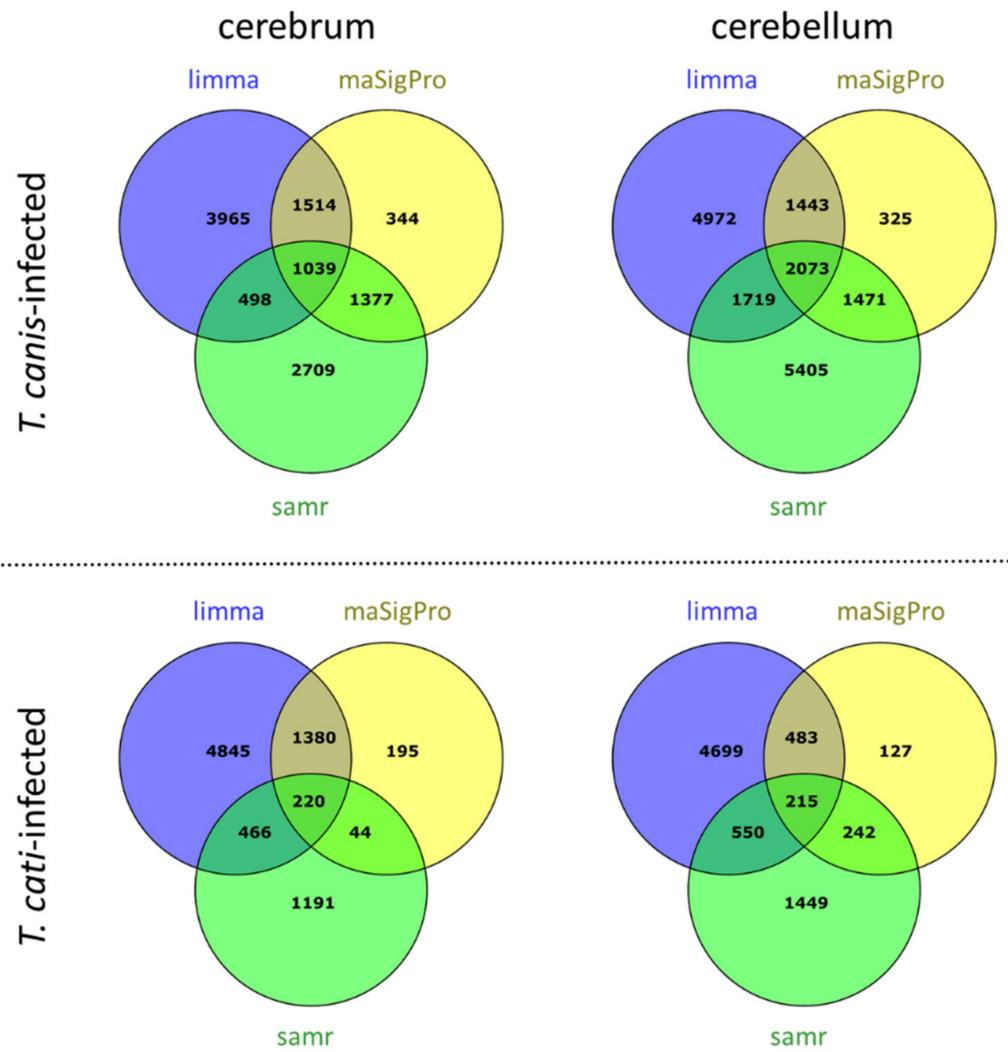

Figure 2. Differentially transcribed genes identified in cerebra and cerebella of T. canis- and T. catiinfected mice over the course of infection. 


\subsection{Differentially Transcribed Microarray Probes and Corresponding Genes in Brains of} T. cati-Infected Mice

During the course of T. cati-induced brain infection, a total of 274 microarray probes were differentially transcribed in the cerebrum, resulting in 220 DTGs (Figure 2), as 48 DTPs could not be annotated and six DTPs were replicates of different genes. A consistent upregulation was observed for six DTGs, while nine DTGs were downregulated at each time point of the analysis, and 205 DTGs varied in their transcriptional regulation during the course of infection.

Cerebellar neuroinvasion of T. cat $i$ was characterized by 263 DTPs, corresponding to 215 identified DTGs, as 35 DTPs could be annotated and 13 DTPs were replicates. The infection evoked the upregulation of 127 DTGs and downregulation of DTGs throughout the course of infection, while the regulation of the remaining 69 DTGs did not show a distinct trend.

\subsection{DTG Overlap in Cerebra and Cerebella of T. canis- and T. cati-Infected Mice}

Comparative DTG analysis showed that 2324 genes were solely dysregulated in either the cerebrum or the cerebellum of T. canis- or T. cati-infected mice, respectively (Figure 3). Regarding DTG overlap, 507 genes were dysregulated in two overlapping subsets, while 63 genes were affected in three overlapping subsets. Only five genes were dysregulated in the cerebrum and cerebellum of T. canis- as well as T. cati-infected mice. Of these five genes, the transcription values of Ighm, Jchain, and Slpi increased progressively during the course of infection in both brain areas of T. canis as well as T. cati-infected mice $(p=0.0294)$ (Figure 4). Transcription of Dnajc21 and Rbm33 was rather downregulated, strikingly with statistically significant decreased values during the chronic phase (as of day $70 \mathrm{pi}$ ) of cerebellar T. canis infection $(p=0.0177)$.

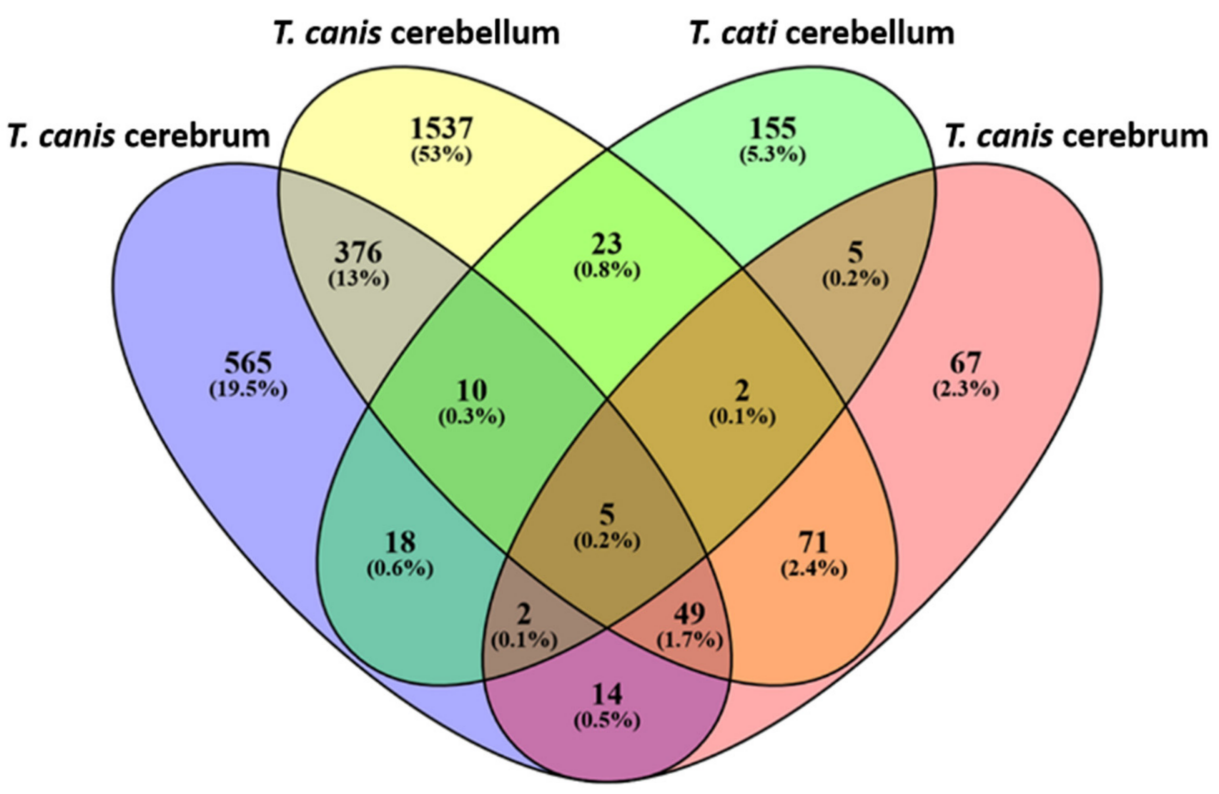

Figure 3. Venn diagram showing number and percentage of specific and overlapping differentially transcribed genes in T. canis- and T. cati-infected cerebra and cerebella. 


\section{Cerebrum}

a)

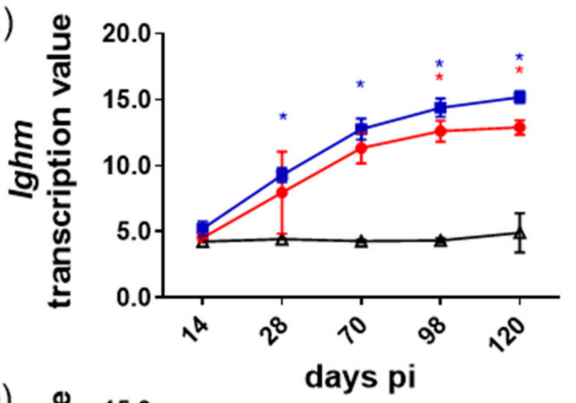

b)

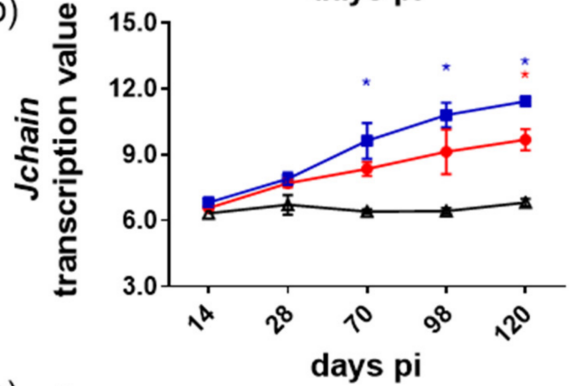

c)

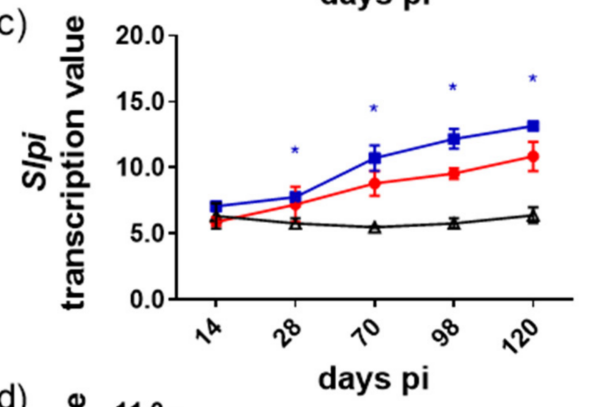

d)

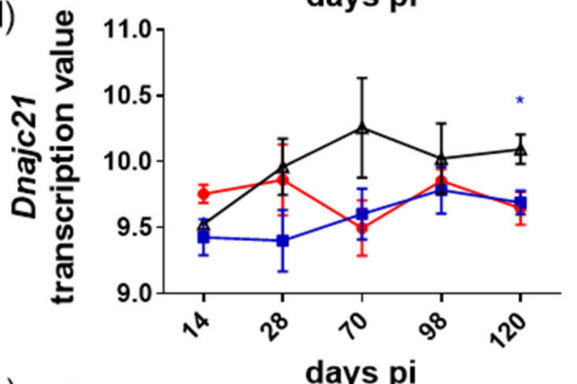

e)

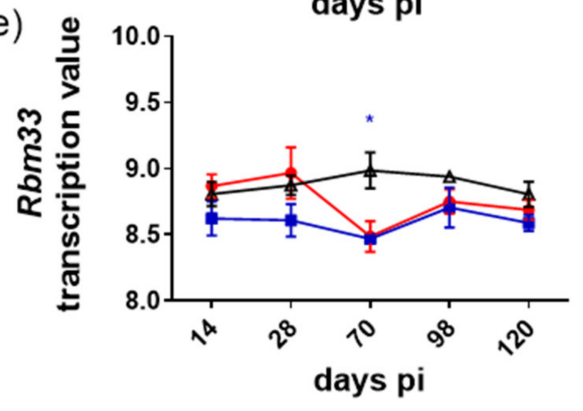

uninfected control

\section{T. canis-infected}

Cerebellum
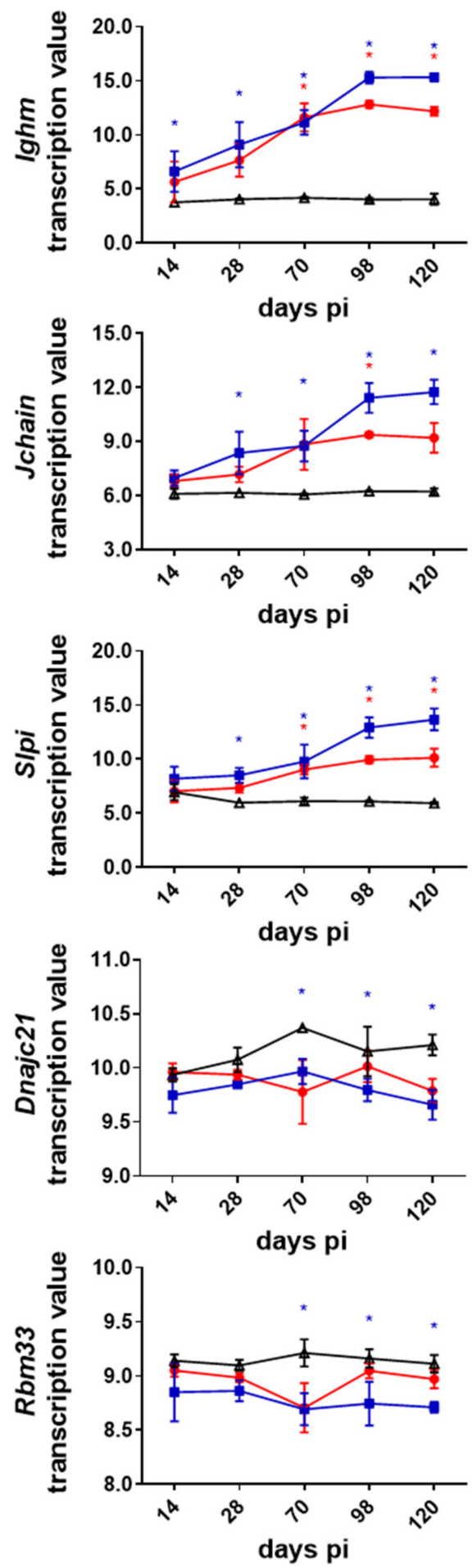

T. cati-infected

Figure 4. Transcriptional values of the five genes (a) Ighm, (b) Jchain, (c) Slpi, (d) Dnajc21, and (e) Rbm33 differentially transcribed in the cerebra and cerebella of both Toxocara. canis- and T. cati-mice at different days post infection (pi). Asterisks indicate statistically significant differences $(p \leq 0.05)$ between infected and uninfected mice according to the color scheme.

\subsection{PANTHER Pathway Analysis of DTGs}

An overview of statistically significantly dysregulated PANTHER pathways in cerebra and cerebella of T. canis-infected mice is given in Table 1. Of the 1039 DTGs in the cerebrum 
of T. canis-infected mice, 915 DTGs mapped uniquely, 21 had multiple mapping information, and 103 could not be mapped in PANTHER pathways. The broad majority of mapped DTGs (790) were marked as "unclassified" and did not cluster in specific pathways. A total of 125 DTGs were mapped in 9 statistically significantly dysregulated pathways. The infection affected the cholesterol biosynthesis (fold enrichment $=10.76$, adj. $p=0.003$ ), including six predominately downregulated genes. In contrast, transcription of the 13 affected DTGs in the interleukin signaling pathway (fold enrichment $=3.44, p=0.005$ ) was mostly upregulated during the course of infection. No distinct trend was observed for the remaining pathways, where genes were either up- or downregulated during the course of infection.

Table 1. Pathways affected by differentially transcribed genes (DTGs) in T. canis-infected cerebra and cerebella. Note that no pathways were statistically significantly overrepresented during T. cati-infection.

\begin{tabular}{|c|c|c|c|c|}
\hline & $\begin{array}{l}\text { Enriched Biological Modules } \\
\text { (Panther Pathway Accession Number) }\end{array}$ & DTGs & Fold-Enrichment & Adj. $p$-Value (FDR) \\
\hline \multirow[t]{10}{*}{ Cerebrum } & Cholesterol biosynthesis (P00014) & 6 & 10.76 & 0.003 \\
\hline & Axon guidance mediated by Slit/Robo (P00008) & 7 & 6.80 & 0.005 \\
\hline & B cell activation (P00010) & 13 & 4.33 & 0.001 \\
\hline & T cell activation (P00053) & 14 & 3.63 & 0.003 \\
\hline & Apoptosis signaling pathway (P00006) & 18 & 3.56 & 0.001 \\
\hline & Interleukin signaling pathway (P00036) & 13 & 3.44 & 0.005 \\
\hline & Ras Pathway (P04393) & 10 & 3.33 & 0.030 \\
\hline & CCKR signaling map (P06959) & 21 & 3.08 & 0.001 \\
\hline & $\begin{array}{l}\text { Inflammation mediated by chemokine and cytokine } \\
\text { signaling pathway (P00031) }\end{array}$ & 23 & 2.08 & 0.034 \\
\hline & Unclassified & 790 & 0.93 & $<0.001$ \\
\hline \multirow[t]{4}{*}{ Cerebellum } & Apoptosis signaling pathway (P00006) & 25 & 2.54 & 0.006 \\
\hline & $\begin{array}{l}\text { Inflammation mediated by chemokine and cytokine } \\
\text { signaling pathway (P00031) }\end{array}$ & 44 & 2.04 & 0.004 \\
\hline & Integrin signaling pathway (P00034) & 32 & 2.02 & 0.023 \\
\hline & Unclassified & 1542 & 0.94 & $<0.001$ \\
\hline
\end{tabular}

In the cerebella of T. canis-infected mice, 249 out of the 2073 DTGs remained unmapped by PANTHER pathways analysis, while 1824 could be mapped. Of these, 1643 DTGs mapped uniquely and 181 had multiple mapping information. While 1542 DTGs were marked as "unclassified", 101 DTGs were dysregulated in three statistically significantly affected pathways; apoptosis signaling, chemokine, and cytokine signaling as well as integrin signaling (Table 1). Within these pathways, the different DTGs did not show a distinct trend, but were either up- or downregulated.

The infection with T. cati resulted in 220 DTGs in the cerebrum, of which 199 DTGs were mapped, while 21 DTGs could not be allocated in specific PANTHER pathways. In the cerebellum, 195 of the 215 DTGs could be mapped and 20 DTGs did not cluster. However, $T$. cati infection did not result in statistically significant transcriptional pathway alterations in either the cerebrum or the cerebellum.

\subsection{Enriched PANTHER Pathways at Different Study Days}

The number of DTGs and statistically significantly affected pathways for each study day during the course of infection are provided in Table 2. The number of downregulated genes in the cerebra of T. canis-infected mice varied from 418 (day 120 pi) to 505 (day 70 pi). The cholesterol biosynthesis was the only pathway with statistically significantly decreased transcription rates at each time point of the study. In the advanced chronic phase of infection, i.e., days 98 and 120 pi, the heterotrimeric G-protein signaling pathway was additionally downregulated. Further pathways like the gonadotropin-releasing hormone receptor pathway or the Alzheimer disease-amyloid secretase pathway were statistically significantly affected by downregulated DTGs at day 120 pi. 
Table 2. Number of differentially transcribed genes (DTGs) in Toxocara canis- and T. cati-infected cerebra and cerebella and enriched biological pathways with an adjusted $p$-value $\leq 0.05$ for each study day.

\begin{tabular}{|c|c|c|c|c|}
\hline & Study Day & Regulation & Number of DTGs & $\begin{array}{c}\text { Enriched Biological Modules } \\
\text { (PANTHER Pathway Accession Number) }\end{array}$ \\
\hline \multicolumn{5}{|l|}{ T. canis } \\
\hline \multirow[t]{10}{*}{ cerebrum } & \multirow[t]{2}{*}{14 pi } & up & 605 & $\begin{array}{l}\text { Apoptosis signaling pathway (P00006), Axon guidance } \\
\text { mediated by Slit/Robo (P00008), B-cell activation (P00010), } \\
\text { CCKR signaling map (P06959), FAS signaling pathway } \\
\text { (P00020), Inflammation mediated by chemokine and } \\
\text { cytokine signaling pathway (P00031), Interleukin signaling } \\
\text { pathway (P00036), JAK/STAT signaling pathway (P00038), } \\
\text { Ras Pathway (P04393), T-cell activation (P00053) }\end{array}$ \\
\hline & & down & 434 & Cholesterol biosynthesis (P00014) \\
\hline & \multirow[t]{2}{*}{$28 \mathrm{pi}$} & up & 539 & $\begin{array}{l}\text { Apoptosis signaling pathway (P00006), B-cell activation } \\
\text { (P00010), CCKR signaling map (P06959), FAS signaling } \\
\text { pathway (P00020), Inflammation mediated by chemokine } \\
\text { and cytokine signaling pathway (P00031), Interleukin } \\
\text { signaling pathway (P00036), JAK/STAT signaling pathway } \\
\text { (P00038), Ras Pathway (P04393), T-cell activation (P00053) }\end{array}$ \\
\hline & & down & 500 & Cholesterol biosynthesis (P00014) \\
\hline & \multirow[t]{2}{*}{$70 \mathrm{pi}$} & up & 534 & $\begin{array}{l}\text { Apoptosis signaling pathway (P00006), Axon guidance } \\
\text { mediated by Slit/Robo (P00008), B-cell activation (P00010), } \\
\text { CCKR signaling map (P06959), FAS signaling pathway } \\
\text { (P00020), Inflammation mediated by chemokine and } \\
\text { cytokine signaling pathway (P00031), Interleukin signaling } \\
\text { pathway (P00036), JAK/STAT signaling pathway (P00038), } \\
\text { Ras Pathway (P04393), T-cell activation (P00053) }\end{array}$ \\
\hline & & down & 505 & Cholesterol biosynthesis (P00014) \\
\hline & \multirow[t]{2}{*}{$98 \mathrm{pi}$} & up & 553 & $\begin{array}{l}\text { Apoptosis signaling pathway (P00006), B-cell activation } \\
\text { (P00010), CCKR signaling map (P06959), FAS signaling } \\
\text { pathway (P00020), Inflammation mediated by chemokine } \\
\text { and cytokine signaling pathway (P00031), Interleukin } \\
\text { signaling pathway (P00036), JAK/STAT signaling pathway } \\
\text { (P00038), Ras Pathway (P04393), T-cell activation (P00053) }\end{array}$ \\
\hline & & down & 486 & $\begin{array}{c}\text { Cholesterol biosynthesis (P00014), Heterotrimeric G-protein } \\
\text { signaling pathway-Gq alpha and Go alpha mediated } \\
\text { pathway (P00026) }\end{array}$ \\
\hline & \multirow{2}{*}{$120 \mathrm{pi}$} & up & 621 & $\begin{array}{l}\text { Apoptosis signaling pathway (P00006), Axon guidance } \\
\text { mediated by Slit/Robo (P00008), B-cell activation (P00010), } \\
\text { CCKR signaling map (P06959), Inflammation mediated by } \\
\text { chemokine and cytokine signaling pathway (P00031), } \\
\text { Interleukin signaling pathway (P00036), JAK/STAT } \\
\text { signaling pathway (P00038), T-cell activation (P00053) }\end{array}$ \\
\hline & & down & 418 & $\begin{array}{c}\text { 5HT2 type receptor-mediated signaling pathway (P04374), } \\
\text { Alzheimer disease-amyloid secretase pathway (P00003), } \\
\text { Cholesterol biosynthesis (P00014), Gonadotropin-releasing } \\
\text { hormone receptor pathway (P06664), Heterotrimeric } \\
\text { G-protein signaling pathway-Gq alpha and Go alpha } \\
\text { mediated pathway (P00026) }\end{array}$ \\
\hline
\end{tabular}


Table 2. Cont.

\begin{tabular}{|c|c|c|c|c|}
\hline & Study Day & Regulation & Number of DTGs & $\begin{array}{c}\text { Enriched Biological Modules } \\
\text { (PANTHER Pathway Accession Number) }\end{array}$ \\
\hline \multirow[t]{10}{*}{ cerebellum } & \multirow[t]{2}{*}{14 pi } & up & 1106 & $\begin{array}{l}\text { Apoptosis signaling pathway (P00006), B-cell activation } \\
\text { (P00010), Inflammation mediated by chemokine and } \\
\text { cytokine signaling pathway (P00031), Interleukin signaling } \\
\text { pathway (P00036), Toll receptor signaling pathway (P00054) }\end{array}$ \\
\hline & & down & 967 & $\mathrm{n} / \mathrm{a}$ \\
\hline & \multirow[t]{2}{*}{$28 \mathrm{pi}$} & up & 1139 & $\begin{array}{c}\text { Apoptosis signaling pathway (P00006), B-cell activation } \\
\text { (P00010), Inflammation mediated by chemokine and } \\
\text { cytokine signaling pathway (P00031), Interleukin signaling } \\
\text { pathway (P00036), T-cell activation (P00053), Toll receptor } \\
\text { signaling pathway (P00054) }\end{array}$ \\
\hline & & down & 934 & $\mathrm{n} / \mathrm{a}$ \\
\hline & \multirow[t]{2}{*}{70 pi } & up & 1017 & $\begin{array}{l}\text { Apoptosis signaling pathway (P00006), B-cell activation } \\
\text { (P00010), Inflammation mediated by chemokine and } \\
\text { cytokine signaling pathway (P00031), Interleukin signaling } \\
\text { pathway (P00036), Plasminogen activating cascade (P00050), } \\
\text { Toll receptor signaling pathway (P00054) }\end{array}$ \\
\hline & & down & 1056 & $\mathrm{n} / \mathrm{a}$ \\
\hline & \multirow[t]{2}{*}{98 pi } & up & 1091 & $\begin{array}{l}\text { Apoptosis signaling pathway (P00006), B-cell activation } \\
\text { (P00010), Inflammation mediated by chemokine and } \\
\text { cytokine signaling pathway (P00031), Interleukin signaling } \\
\text { pathway (P00036), JAK/STAT signaling pathway (P00038), } \\
\text { Plasminogen activating cascade (P00050), Toll receptor } \\
\text { signaling pathway (P00054) }\end{array}$ \\
\hline & & down & 982 & $\mathrm{n} / \mathrm{a}$ \\
\hline & \multirow[t]{2}{*}{$120 \mathrm{pi}$} & up & 1084 & $\begin{array}{c}\text { Apoptosis signaling pathway (P00006), B-cell activation } \\
\text { (P00010), Cadherin signaling pathway (P00012), } \\
\text { Inflammation mediated by chemokine and cytokine } \\
\text { signaling pathway (P00031), Interleukin signaling pathway } \\
\text { (P00036), JAK/STAT signaling pathway (P00038), } \\
\text { Plasminogen activating cascade (P00050), Toll receptor } \\
\text { signaling pathway (P00054) }\end{array}$ \\
\hline & & down & 989 & $\mathrm{n} / \mathrm{a}$ \\
\hline \multirow[t]{10}{*}{$\begin{array}{l}\text { T. cati } \\
\text { cerebrum }\end{array}$} & \multirow{2}{*}{14 pi } & up & 150 & $\mathrm{n} / \mathrm{a}$ \\
\hline & & down & 70 & $\mathrm{n} / \mathrm{a}$ \\
\hline & \multirow{2}{*}{$28 \mathrm{pi}$} & up & 165 & $\mathrm{n} / \mathrm{a}$ \\
\hline & & down & 55 & $\mathrm{n} / \mathrm{a}$ \\
\hline & \multirow{2}{*}{70 pi } & up & 168 & $\mathrm{n} / \mathrm{a}$ \\
\hline & & down & 52 & $\mathrm{n} / \mathrm{a}$ \\
\hline & \multirow{2}{*}{98 pi } & up & 158 & $\mathrm{n} / \mathrm{a}$ \\
\hline & & down & 62 & $\mathrm{n} / \mathrm{a}$ \\
\hline & \multirow{2}{*}{$120 \mathrm{pi}$} & up & 142 & $\mathrm{n} / \mathrm{a}$ \\
\hline & & down & 78 & $\mathrm{n} / \mathrm{a}$ \\
\hline
\end{tabular}


Table 2. Cont.

\begin{tabular}{|c|c|c|c|c|}
\hline & Study Day & Regulation & Number of DTGs & $\begin{array}{l}\text { Enriched Biological Modules } \\
\text { (PANTHER Pathway Accession Number) }\end{array}$ \\
\hline \multirow[t]{10}{*}{ cerebellum } & \multirow{2}{*}{$14 \mathrm{pi}$} & up & 163 & $\mathrm{n} / \mathrm{a}$ \\
\hline & & down & 52 & $\mathrm{n} / \mathrm{a}$ \\
\hline & \multirow{2}{*}{28 pi } & up & 161 & $\mathrm{n} / \mathrm{a}$ \\
\hline & & down & 54 & $\mathrm{n} / \mathrm{a}$ \\
\hline & \multirow{2}{*}{70 pi } & up & 161 & $\mathrm{n} / \mathrm{a}$ \\
\hline & & down & 54 & $\mathrm{n} / \mathrm{a}$ \\
\hline & \multirow{2}{*}{98 pi } & up & 161 & $\mathrm{n} / \mathrm{a}$ \\
\hline & & down & 54 & $\mathrm{n} / \mathrm{a}$ \\
\hline & \multirow{2}{*}{$120 \mathrm{pi}$} & up & 160 & $\mathrm{n} / \mathrm{a}$ \\
\hline & & down & 55 & $\mathrm{n} / \mathrm{a}$ \\
\hline
\end{tabular}

n/a: no significantly enriched biological modules.

The number of upregulated genes in the cerebra of T. canis-infected mice varied between 534 DTGs at day 70 pi and 621 DTGs at day 120 pi. Gene transcription of DTGs in the apoptosis-, JAK/STAT-, Interleukin-, CCKR- and chemokine and cytokine-mediated signaling pathways as well as the B- and T-cell activation was mostly upregulated throughout the whole study period. Additionally, the Ras pathway was significantly affected at days $14,28,70$, and $98 \mathrm{pi}$, and the Slit/Robo mediated axon guidance pathway at days 14,70 , and 120 pi by upregulated DTGs. In the FAS signaling pathway, DTGs were significantly upregulated in the subacute phase (days 14 and 28 pi) and the beginning of the chronic phase (day 70 pi) of infection.

In the cerebella of T. canis-infected mice, the number of downregulated DTGs varied between 934 DTGs at day 28 pi and 1091 DTGs at day 98 pi, but no particular pathway was overrepresented in the PANTHER pathway analysis. Upregulation of genes varied between 1017 DTGs at day 70 pi and 1139 DTGs at day 28 pi. During the entire study period, the Toll receptor-, Apoptosis-, Interleukin- and chemokine and cytokine-mediated signaling, as well as the B-cell activation pathway, included statistically significant numbers of upregulated DTGs. The T-cell activation and the Cadherin signaling pathway were significantly affected in the subacute phase of infection at day 28 as well as the latest time point of the analysis, day $120 \mathrm{pi}$. The Plasminogen activating cascade and the JAK/STAT signaling pathway were significantly altered in the chronic phase-only i.e., at days 70,98 , and 120 pi and days 98 and 120 pi.

During the course of infection with T. cati, the number of downregulated genes varied between 52 DTGs and 78 DTGs at days 70 and 120 pi in the cerebra and between 52 DTGs and 55 DTGs at days 14 and 120 pi in the cerebella. Upregulation of DTGs in the cerebra of T. cati-infected mice varied between 142 DTGs at day 120 pi and 168 DTGs at day 70 pi. In the cerebella, the range of upregulated DTGs was 160 DTGs at day 120 pi and 163 DTGs at day 14 pi. However, although the infection with $T$. cati resulted in differentially transcribed genes in both brain parts, no particular pathway was statistically significantly affected.

\section{Discussion}

The progressive migration and accumulation of larvae in somatic and cerebral tissues classifies NT into an acute (approx. until day 14 pi), subacute (approx. until day 28 pi), and subsequent chronic phase of infection [15]. The course of infection is characterized by the onset of neurobehavioral changes and inflammatory reactions in the brain of infected paratenic hosts in the acute and subacute phase, as well as progressively increasing behavioral and pathological effects during the chronic phase [20,31,32]. The CNS manifestation in humans is associated with different neuropsychological disorders and cognitive 
deficits $[7,8,11-14]$. Furthermore, murine NT, used as a model for human NT, is characterized by neurological and motor dysfunctions, reduced levels of aggressive behavior and anxiety as well as impairments of learning and memory capacity [30,32,33]. Larval migration into the cerebral tissues causes parenchymal damage with macroscopically visible hemorrhagic lesions, while the further course of infection results in neurodegenerative processes $[20,21,31,34]$. Although larvae of $T$. canis are regarded as the common causative agent of human NT, T. cat $i$ is also capable of inducing NT [15-18]. Neurological disorders and histopathological alterations are prominent in both infections, but the progression of the disease is pronounced in T. canis-induced infections [15,19,21,31,35]. These differences in the severity of NT are reflected by alterations in transcriptomic profiles of both infection groups in the present study. The combined SAM, limma and maSigPro microarray analysis resulted in a considerably higher number of DTGs in T. canis-infected mice compared to T. cati-infected mice, with 1239 and 2544 DTGs in the cerebrum and the cerebellum of T. canis-infected mice. In contrast, only 274 and 263 DTGs were identified in the cerebrum and cerebellum upon T. cati infection. These differences are further evident at the particular study days, where the number of DTGs was always higher in both brain parts of the T. canis-infected mice than in the T. cati-infected mice. Nevertheless, five genes were dysregulated in the cerebrum as well as the cerebellum by both pathogens. Interestingly, three of them-Ighm, Jchain, and Slpi-showed the same pattern in terms of a progressive increase during the course of infection in both brain parts and infection groups. These genes are involved in general immune reactions, as Ighm and Jchain encode parts of immunoglobulins and Slpi encodes a secreted inhibitor that protects epithelial tissues [36-38].

Individual DTGs were categorized by PANTHER classification, revealing the cholesterol biosynthesis pathway as one of the most affected pathways in the cerebrum of T. canisinfected mice. Cholesterol is an important structural component for cellular membranes, a precursor of steroid hormones, and mandatory in myelin formation, enabling the saltatory conduction of action potentials by discontinuous insulation of neurons [39]. Therefore, cholesterol is necessary for the maintenance of the synaptic function of neurons, and depletion of cholesterol with synaptic loss is frequently observed in neurodegenerative diseases [40]. Interestingly, transcription of genes in this pathway was predominantly decreased during the whole course of infection. Compared to the uninfected control group, DTGs of other pathways were downregulated only in the chronic phase at days 98 and 120 pi or upregulated during the study period. Transcription rates of genes involved in the cholesterol pathway also decrease during neuroinfection with Neospora caninum as well as in scrapie-inoculated mice, resulting in the exacerbation of neuronal damage, neurodegeneration, impaired regeneration of damaged neuronal tissues, and the disruption of neurotransmission [41,42].

Along with decreased transcriptions in the cholesterol biosynthesis pathway, the infection with $T$. canis was characterized by elevated mRNA levels of genes associated with the apoptosis signaling pathway. Dysregulation of apoptotic processes has been linked to numerous pathologies, such as chronic inflammation and neurodegenerative diseases like Alzheimer's and Parkinson's diseases [43]. Infections with T. canis are characterized by progressive neuronal demyelination with a focal accumulation of gitter cells, displaying myelinophagia as well as spheroids and cholesterol crystals, indicating axonal damage $[20,31,44]$. The significant dysregulation of cholesterol biosynthesis, as well as the upregulation of the apoptosis signaling pathway, may promote the pathological outcome of NT, but further studies are required to strengthen this hypothesis.

Upon T. cati infection, however, neither the cholesterol biosynthesis nor the apoptosis signaling pathway was significantly affected compared to the uninfected control mice. Assuming a predominant role of these pathways in the clinical outcome of NT, the less severe progression of the T. cati-induced disease may be reflected by the transcriptional outcome of this study.

Further dysregulated pathways during T. canis infection participate in neuroinflammatory processes and the cerebral immune response, e.g., the B- and T-cell activation or 
the chemokine and cytokine-mediated signaling pathways. Host- or parasite-induced immunoregulatory processes may contribute to the pathogenesis of NT, but detailed data on the involvement of signaling molecules during cerebral Toxocara infections are scarce [15]. Important molecules involved in the complex molecular signaling network in infection and inflammation are cytokines and chemokines as well as polyunsaturated fatty acid-derived bioactive regulatory lipids such as oxylipins. Neuroinvasion of larvae did not have a promoting effect on metabolite concentrations of pro-inflammatory mediators like TNF- $\alpha$, IFN- $\gamma$, GM-CSF, and IL-6 [22], but led to a prominent increase in anti-inflammatory immunoregulative molecules in infected brains, including cytokines IL-4, IL-5, the chemokine eotaxin, and 12/15-LOX-products, e.g. 13-HODE or neuroprotectin D1 [22,23]. The increase in anti-inflammatory cytokines and chemokines is also reflected at the microarray level, as pathways like the interleukin signaling pathway or the inflammation mediated by chemokine and cytokine signaling pathway were affected by brain infection with $T$. canis. However, an encompassing trend in the transcriptional regulation of the neuroinflammatory pathways was not observed as genes were either up- or downregulated during the course of infection.

Although infection with T. canis resulted in elevated numbers of DTGs in the cerebellum, only three pathways were significantly dysregulated during the course of infection. Along with apoptosis signaling and inflammation mediated by chemokine and cytokine signaling, the integrin signaling pathway was influenced by neuroinvasive T. canis larvae. Integrins, as transmembrane adhesion receptors, mediate cell-cell and cell-extracellular matrix adhesion, influence various signal transduction cascades in control of cell survival, proliferation, differentiation, and organ development [45]. Furthermore, integrinmediated adhesive interactions are essential in regulating different selective cell responses, such as transmigration into the inflammatory site, cytokine secretion, and production of reactive oxygen intermediation of polymorphonuclear leukocytes (PMNs) as well as monocyte/macrophages [46]. These interactions may participate in the NT-characteristic infiltration of eosinophilic granulocytes in cerebral tissues [20,47]. Different genes of the integrin signaling pathway were downregulated in our analysis, while transcriptional levels of Itgax (CD11c), encoding the integrin subunit alpha X, were elevated in cerebra of T. canis-infected mice. CD11c seems to play a major role in inducing the Th2 response, as gene depletion resulted in an impaired Th2 cytokine profile to a stimulus with Schistosoma mansoni [48]. Interestingly, the cerebral immune response in T. canis-induced NT evokes a Th2-polarised immune reaction [23].

Despite the progressive course of NT, most pathways identified as overrepresented in the day-wise PANTHER classification were dysregulated in both the cerebra and cerebella of T. canis-infected mice at the most examined time points. Pathways predominately associated with the immune response, but also the apoptosis signaling pathway showed continuously increased transcription rates. Constantly decreased transcriptional levels at each study day could be detected in the cerebra of T. canis-infected mice only for genes associated with cholesterol biosynthesis. Additionally, the number of dysregulated pathways with decreased transcriptional levels increased in the advanced chronic phase of infection. Of these, the Alzheimer disease-amyloid secretase pathway affected at day $120 \mathrm{pi}$ is of particular interest in terms of neurodegeneration as a consequence of Toxocara neuroinvasion. Furthermore, T. canis is discussed as a potential causative agent for Alzheimer's disease (AD) $[8,20,24]$. Axonal damage upon NT is indicated by accumulated $\beta$-amyloid precursor protein ( $\beta$-APP), which, in combination with its derivatives like the amyloid $\beta$ protein $(\mathrm{A} \beta)$ plays a pivotal role in AD [49]. During the analysis, DTGs included in the Alzheimer disease-amyloid secretase pathway were Prkcd (protein kinase $C \delta$ [PKC- $\delta]$ ) and Mapk10 (mitogen-activated protein kinase 10 [Mapk10]). Stimulation of microglia with A $\beta$ increased the kinase activity of PKC- $\delta[50]$, and PKC- $\delta$ expression is elevated in human AD, correlating with beta-site APP cleaving enzyme 1 (BACE1) expression in BACE1-mediated $\beta$-APP processing as well as A $\beta$ production [51]. Furthermore, patients with AD had significantly increased levels of Mapk10, associated with $A \beta$ in senile plaques [52]. 
A further dysregulated pathway with decreased transcriptional levels compared to the uninfected control mice was the gonadotropin-releasing hormone $(\mathrm{GnRH})$ receptor pathway. The peptide GnRH is primarily known to participate in the regulation of reproduction via the hypothalamic-pituitary-gonadal axis, but may also serve as a neurotrophic factor and modulator of hippocampal synaptic activities, impacting central nervous system physiology as well as pathophysiology [53-56]. Reduced levels of GnRH may contribute to the development of $\mathrm{AD}$ pathology, as the treatment with $\mathrm{GnRH}$ lowered hippocampal plaque load, reduced the $A \beta$ concentration in brains of C57BL/ 6 mice, and prevented AD-related cognitive dysfunctions $[57,58]$. Additionally, inflammatory processes in the hypothalamus of aged mice result in downregulation of GnRH expression [59]. Cognitive function deficits are also associated with deficiency of the growth hormone (GH), another hypothalamic hormone-induced, for example, by traumatic brain injuries [60-62]. Interestingly, memory impairment, as well as cognitive dysfunction, have also been described as a consequence of NT in humans $[8,12,14]$.

The infection with T. canis resulted in a higher number of DTGs in the cerebellum than in the cerebrum, but PANTHER Classification analysis resulted in a higher number of affected pathways in the cerebrum, which may reflect the described species-specific brain part tropism of $T$. canis larvae in paratenic hosts [31]. In contrast, $T$. cati larvae rather migrate to the cerebellum than to the cerebrum, but larvae mainly accumulate in muscle tissue [31]. Consequently, fewer DTGs were observed in the brain of $T$. cati-infected mice and no particular pathway was overrepresented during the PANTHER Classification analysis. This mirrors previous observations in T. cati-infected C57BL/6J mice, which showed delayed onset and less severe progression of neurobehavioral alterations as well as less severe histopathological alterations compared to T. canis-infected mice $[15,21,30]$.

Finally, an important point to mention is that NT is characterized by focally distributed lesions, so healthy brain tissue was most likely overrepresented in the transcriptional analysis compared to damaged tissue. This may have masked local effects induced by migrating or persisting $T$. cati larvae, and may have reduced observed effects of $T$. canis larvae on both brain parts.

\section{Conclusions}

T. canis- and T. cati-induced neurotoxocarosis in the paratenic mouse model was associated with the comprehensive transcriptional alteration. Nevertheless, the known differences between the pathogens were reflected by substantially higher numbers of DTGs in brain tissues of T. canis- compared to T. cati-infected mice. The prominent pathogenesis of $T$. canis-induced NT was also evident in the affected pathways. While the PANTHER analysis of DTGs in brains of T. cati-infected mice did not result in the overrepresentation of specific pathways, neuroinvasion of T. canis larvae evoke dysregulation of various pathways associated with the immune response. Furthermore, cerebral transcription of genes associated with cholesterol biosynthesis was constantly decreased during the course of infection, suggesting a fundamental impact of neuroinvasive T. canis larvae on cholesterol homeostasis. Dysregulation of the cholesterol biosynthesis pathway may provoke neurodegeneration, a typical hallmark of NT. Thus, axonal damage in conjunction with the dysregulated Alzheimer disease-amyloid secretase pathway promotes the discussion of $T$. canis as a causative agent for Alzheimer's disease. Further research investigating these and other topics is required to characterize the still largely unknown pathogenesis of T. canis- and T. cati-induced NT and to develop new diagnostic and therapeutic approaches.

Author Contributions: Conceptualization, C.S.; investigation, E.J.-E., D.L.L., E.W., K.S., and R.G.; validation, K.S. and R.G.; formal analysis, P.W. and D.L.L.; resources, K.S., R.G., and C.S.; data curation, P.W. and D.L.L.; visualization, P.W.; writing-original draft preparation, P.W.; writingreview and editing, E.J.-E., D.L.L., E.W., R.G., and C.S.; supervision, C.S.; project administration, C.S.; Funding acquisition, K.S. All authors have read and agreed to the published version of the manuscript. 
Funding: This work was supported by intra-mural grants from the Helmholtz Association (Program Infection and Immunity) awarded to K.S.

Institutional Review Board Statement: Animal experiments were performed in accordance with the German Animal Welfare act in addition to national and international guidelines for animal welfare. Experiments were permitted by the Ethics Commission of the Animal Care and Use Committee of the German Lower Saxony State Office for Consumer Protection and Food Safety (Niedersaechsisches Landesamt für Verbraucherschutz und Lebensmittelsicherheit) under reference numbers 33.9-42502-0501A038 and 33.14-42502-04-12/0790.

Informed Consent Statement: Not applicable.

Data Availability Statement: The microarray data set is available at the Gene Expression Omnibus (GEO) database of the National Center for Biotechnology Information (NCBI) under the accession number GSE190123.

Acknowledgments: The authors wish to thank Ulla Küttler and Lea Heuer for their excellent technical assistance. This publication was supported by Deutsche Forschungsgemeinschaft and University of Veterinary Medicine Hannover, Foundation within the funding programme Open Access Publishing.

Conflicts of Interest: The authors declare no conflict of interest.

\section{References}

1. Miller, A.D. Pathology of larvae and adults in dogs and cats. Adv. Parasitol. 2020, 109, 537-544. [PubMed]

2. Rostami, A.; Riahi, S.M.; Hofmann, A.; Ma, G.; Wang, T.; Behniafar, H.; Taghipour, A.; Fakhri, Y.; Spotin, A.; Chang, B.C.H.; et al. Global prevalence of Toxocara infection in dogs. Adv. Parasitol. 2020, 109, 561-583. [PubMed]

3. Rostami, A.; Sepidarkish, M.; Ma, G.; Wang, T.; Ebrahimi, M.; Fakhri, Y.; Mirjalali, H.; Hofmann, A.; Macpherson, C.N.L.; Hotez, P.J.; et al. Global prevalence of 615-639 infection in cats. Adv. Parasitol. 2020, 109, 615-639. [PubMed]

4. Rubinsky-Elefant, G.; Hirata, C.E.; Yamamoto, J.H.; Ferreira, M.U. Human toxocariasis: Diagnosis, worldwide seroprevalences and clinical expression of the systemic and ocular forms. Ann. Trop. Med. Parasitol. 2010, 104, 3-23. [CrossRef]

5. Rostami, A.; Riahi, S.M.; Holland, C.V.; Taghipour, A.; Khalili-Fomeshi, M.; Fakhri, Y.; Omrani, V.F.; Hotez, P.J.; Gasser, R.B. Seroprevalence estimates for toxocariasis in people worldwide: A systematic review and meta-analysis. PLoS Negl. Trop. Dis. 2019, 13, e0007809. [CrossRef] [PubMed]

6. Macpherson, C.N. The epidemiology and public health importance of toxocariasis: A zoonosis of global importance. Int. J. Parasitol. 2013, 43, 999-1008. [CrossRef]

7. Finsterer, J.; Auer, H. Neurotoxocarosis. Rev. Inst. Med. Trop. Sao Paulo 2007, 49, 279-287. [CrossRef] [PubMed]

8. Fan, C.K.; Holland, C.V.; Loxton, K.; Barghouth, U. Cerebral Toxocariasis: Silent progression to neurodegenerative disorders? Clin. Microbiol. Rev. 2015, 28, 663-686. [CrossRef]

9. Holland, C.V.; Hamilton, C.M. The significance of cerebral toxocariasis: A model system for exploring the link between brain involvement, behaviour and the immune response. J. Exp. Biol. 2013, 216, 78-83. [CrossRef] [PubMed]

10. Hotez, P.J.; Wilkins, P.P. Toxocariasis: America's most common neglected infection of poverty and a helminthiasis of global importance? PLoS Negl. Trop. Dis. 2009, 3, e400. [CrossRef]

11. Eberhardt, O.; Bialek, R.; Nagele, T.; Dichgans, J. Eosinophilic meningomyelitis in toxocariasis: Case report and review of the literature. Clin. Neurol. Neurosurg. 2005, 107, 432-438. [CrossRef]

12. Richartz, E.; Buchkremer, G. Cerebral toxocariasis: A rare cause of cognitive disorders. A contribution to differential dementia diagnosis. Der Nervenarzt 2002, 73, 458-462. [CrossRef]

13. El-Sayed, N.M.; Ismail, K.A. Relationship between Toxocara canis infection and schizophrenia. Rawal Med. J. 2012, 37, 155-161.

14. Walsh, M.G.; Haseeb, M.A. Reduced cognitive function in children with toxocariasis in a nationally representative sample of the United States. Int. J. Parasitol. 2012, 42, 1159-1163. [CrossRef] [PubMed]

15. Strube, C.; Waindok, P.; Raulf, M.K.; Springer, A. Toxocara-induced neural larva migrans (neurotoxocarosis) in rodent model hosts. Adv. Parasitol. 2020, 109, 189-218. [PubMed]

16. Fisher, M. Toxocara cati: An underestimated zoonotic agent. Trends Parasitol. 2003, 19, 167-170. [CrossRef]

17. Smith, H.; Holland, C.; Taylor, M.; Magnaval, J.; Schantz, P.; Maizels, R. How common is human toxocariasis? Towards standardizing our knowledge. Trends Parasitol. 2009, 25, 182-188. [CrossRef] [PubMed]

18. Fukae, J.; Kawanabe, T.; Akao, N.; Kado, M.; Tokoro, M.; Yokoyama, K.; Hattori, N. Longitudinal myelitis caused by visceral larva migrans associated with Toxocara cati infection: Case report. Clin. Neurol. Neurosurg. 2012, 114, 1091-1094. [CrossRef] [PubMed]

19. Epe, C.; Sabel, T.; Schnieder, T.; Stoye, M. The behavior and pathogenicity of Toxacara canis larvae in mice of different strains. Parasitol. Res. 1994, 80, 691-695. [CrossRef]

20. Springer, A.; Heuer, L.; Janecek-Erfurth, E.; Beineke, A.; Strube, C. Histopathological characterization of Toxocara canis- and T. cati-induced neurotoxocarosis in the mouse model. Parasitol. Res. 2019, 118, 2591-2600. [CrossRef] 
21. Heuer, L.; Beyerbach, M.; Lühder, F.; Beineke, A.; Strube, C. Neurotoxocarosis alters myelin protein gene transcription and expression. Parasitol. Res. 2015, 114, 2175-2186. [CrossRef]

22. Waindok, P.; Janecek-Erfurth, E.; Lindenwald, D.; Wilk, E.; Schughart, K.; Geffers, R.; Balas, L.; Durand, T.; Rund, K.M.; Schebb, N.H.; et al. Multiplex profiling of inflammation-related bioactive lipid mediators in Toxocara canis- and Toxocara cati-induced neurotoxocarosis. PLoS Negl. Trop. Dis. 2019, 13, e0007706. [CrossRef]

23. Waindok, P.; Strube, C. Neuroinvasion of Toxocara canis- and T. cati-larvae mediates dynamic changes in brain cytokine and chemokine profile. J. Neuroinflammation 2019, 16, 147. [CrossRef]

24. Janecek, E.; Wilk, E.; Schughart, K.; Geffers, R.; Strube, C. Microarray gene expression analysis reveals major differences between Toxocara canis and Toxocara cati neurotoxocarosis and involvement of T. canis in lipid biosynthetic processes. Int. J. Parasitol. 2015, 45, 495-503. [CrossRef]

25. Pommerenke, C.; Wilk, E.; Srivastava, B.; Schulze, A.; Novoselova, N.; Geffers, R.; Schughart, K. Global transcriptome analysis in influenza-infected mouse lungs reveals the kinetics of innate and adaptive host immune responses. PLoS ONE 2012, 7, e41169. [CrossRef]

26. R Core Team. A Language and Environment for Statistical Computing; R Foundation for Statistical Computing: Vienna, Austria, 2013; Available online: https: / / www.R-project.org (accessed on 13 January 2021).

27. Oliveros, J.C. Venny. An Interactive Tool for Comparing Lists with Venn's Diagrams 2007-2015. Available online: https: / / bioinfogp.cnb.csic.es/tools/venny/index.html (accessed on 25 November 2021).

28. Mi, H.; Ebert, D.; Muruganujan, A.; Mills, C.; Albou, L.P.; Mushayamaha, T.; Thomas, P.D. PANTHER version 16: A revised family classification, tree-based classification tool, enhancer regions and extensive API. Nucleic Acids Res. 2021, 49, D394-D403. [CrossRef] [PubMed]

29. Mi, H.; Thomas, P. PANTHER pathway: An ontology-based pathway database coupled with data analysis tools. Methods Mol. Biol. 2009, 563, 123-140. [PubMed]

30. Janecek, E.; Waindok, P.; Bankstahl, M.; Strube, C. Abnormal neurobehaviour and impaired memory function as a consequence of Toxocara canis-as well as Toxocara cati-induced neurotoxocarosis. PLoS Negl. Trop. Dis. 2017, 11, e0005594. [CrossRef] [PubMed]

31. Janecek, E.; Beineke, A.; Schnieder, T.; Strube, C. Neurotoxocarosis: Marked preference of Toxocara canis for the cerebrum and T. cati for the cerebellum in the paratenic model host mouse. Parasit. Vectors 2014, 7, 194. [CrossRef]

32. Cox, D.M.; Holland, C.V. Relationship between three intensity levels of Toxocara canis larvae in the brain and effects on exploration, anxiety, learning and memory in the murine host. J. Helminthol. 2001, 75, 33-41. [CrossRef]

33. Hamilton, C.M.; Stafford, P.; Pinelli, E.; Holland, C.V. A murine model for cerebral toxocariasis: Characterization of host susceptibility and behaviour. Parasitology 2006, 132, 791-801. [CrossRef]

34. Cardillo, N.; Rosa, A.; Ribicich, M.; Lopez, C.; Sommerfelt, I. Experimental infection with Toxocara cati in BALB/c mice, migratory behaviour and pathological changes. Zoonoses Public Health 2009, 56, 198-205. [CrossRef] [PubMed]

35. Dolinsky, Z.S.; Hardy, C.A.; Burright, R.G.; Donovick, P.J. The progression of behavioral and pathological effects of the parasite Toxocara canis in the mouse. Physiol. Behav. 1985, 35, 33-42. [CrossRef]

36. Friedlander, R.M.; Nussenzweig, M.C.; Leder, P. Complete nucleotide sequence of the membrane form of the human IgM heavy chain. Nucleic Acids Res. 1990, 18, 4278. [CrossRef] [PubMed]

37. Max, E.E.; Korsmeyer, S.J. Human J chain gene. Structure and expression in B lymphoid cells. J. Exp. Med. 1985, 161, 832-849. [CrossRef]

38. Stetler, G.; Brewer, M.T.; Thompson, R.C. Isolation and sequence of a human gene encoding a potent inhibitor of leukocyte proteases. Nucleic Acids Res. 1986, 14, 7883-7896. [CrossRef] [PubMed]

39. Zhang, J.; Liu, Q. Cholesterol metabolism and homeostasis in the brain. Protein Cell 2015, 6, 254-264. [CrossRef]

40. Hering, H.; Lin, C.C.; Sheng, M. Lipid rafts in the maintenance of synapses, dendritic spines, and surface AMPA receptor stability. J. Neurosci. 2003, 23, 3262-3271. [CrossRef]

41. Xiang, W.; Hummel, M.; Mitteregger, G.; Pace, C.; Windl, O.; Mansmann, U.; Kretzschmar, H.A. Transcriptome analysis reveals altered cholesterol metabolism during the neurodegeneration in mouse scrapie model. J. Neurochem. 2007, 102, 834-847. [CrossRef]

42. Nishimura, M.; Tanaka, S.; Ihara, F.; Muroi, Y.; Yamagishi, J.; Furuoka, H.; Suzuki, Y.; Nishikawa, Y. Transcriptome and histopathological changes in mouse brain infected with Neospora Caninum. Sci. Rep. 2015, 5, 7936. [CrossRef] [PubMed]

43. Fulda, S.; Gorman, A.M.; Hori, O.; Samali, A. Cellular stress responses: Cell survival and cell death. Int. J. Cell Biol. 2010, 2010, 214074. [CrossRef] [PubMed]

44. Resende, N.M.; Gazzinelli-Guimarães, P.H.; Barbosa, F.S.; Oliveira, L.M.; Nogueira, D.S.; Gazzinelli-Guimarães, A.C.; Gonçalves, M.T.P.; Amorim, C.C.; Oliveira, F.M.; Caliari, M.V. New insights into the immunopathology of early Toxocara canis infection in mice. Parasit Vectors 2015, 8, 354. [CrossRef] [PubMed]

45. Hynes, R.O. Integrins: Bidirectional, allosteric signaling machines. Cell 2002, 110, 673-687. [CrossRef]

46. Berton, G.; Lowell, C.A. Integrin signaling in neutrophils and macrophages. Cell Signal 1999, 11, 621-635. [CrossRef]

47. Kolbekova, P.; Vetvicka, D.; Svoboda, J.; Skirnisson, K.; Leissova, M.; Syrucek, M.; Mareckova, H.; Kolarova, L. Toxocara canis larvae reinfecting BALB/c mice exhibit accelerated speed of migration to the host CNS. Parasitol. Res. 2011, 109, 1267-1278. [CrossRef] [PubMed] 
48. Phythian-Adams, A.T.; Cook, P.C.; Lundie, R.J.; Jones, L.H.; Smith, K.A.; Barr, T.A.; Hochweller, K.; Anderton, S.M.; Hammerling, G.J.; Maizels, R.M.; et al. CD11c depletion severely disrupts Th2 induction and development in vivo. J. Exp. Med. 2010, 207, 2089-2096. [CrossRef]

49. Bayer, T.A.; Wirths, O.; Majtenyi, K.; Hartmann, T.; Multhaup, G.; Beyreuther, K.; Czech, C. Key factors in Alzheimer's disease: Beta-amyloid precursor protein processing, metabolism and intraneuronal transport. Brain Pathol. 2001, 11, 1-11. [CrossRef]

50. Nakai, M.; Tanimukai, S.; Yagi, K.; Saito, N.; Taniguchi, T.; Terashima, A.; Kawamata, T.; Yamamoto, H.; Fukunaga, K.; Miyamoto, E.; et al. Amyloid beta protein activates PKC-delta and induces translocation of myristoylated alanine-rich C kinase substrate (MARCKS) in microglia. Neurochem. Int. 2001, 38, 593-600. [CrossRef]

51. Du, Y.; Zhao, Y.J.; Li, C.; Zheng, Q.Y.; Tian, J.; Li, Z.Y.; Huang, T.Y.; Zhang, W.; Xu, H.X. Inhibition of PKC delta reduces amyloid-beta levels and reverses Alzheimer disease phenotypes. J. Exp. Med. 2018, 215, 1665-1677. [CrossRef]

52. Gourmaud, S.; Paquet, C.; Dumurgier, J.; Pace, C.; Bouras, C.; Gray, F.; Laplanche, J.L.; Meurs, E.F.; Mouton-Liger, F.; Hugon, J. Increased levels of cerebrospinal fluid JNK3 associated with amyloid pathology: Links to cognitive decline. J. Psychiatry Neurosci. 2015, 40, 151-161. [CrossRef]

53. Meethal, S.V.; Smith, M.A.; Bowen, R.L.; Atwood, C.S. The gonadotropin connection in Alzheimer's disease. Endocrine 2005, 26, 317-326. [CrossRef]

54. Wang, L.; Chadwick, W.; Park, S.S.; Zhou, Y.; Silver, N.; Martin, B.; Maudsley, S. Gonadotropin-releasing hormone receptor system: Modulatory role in aging and neurodegeneration. CNS Neurol. Disord. Drug Targets 2010, 9, 651-660. [CrossRef] [PubMed]

55. Stevenson, T.J.; Hahn, T.P.; MacDougall-Shackleton, S.A.; Ball, G.F. Gonadotropin-releasing hormone plasticity: A comparative perspective. Front. Neuroendocr. 2012, 33, 287-300. [CrossRef] [PubMed]

56. Nuruddin, S.; Syverstad, G.H.; Lillehaug, S.; Leergaard, T.B.; Nilsson, L.N.; Ropstad, E.; Krogenaes, A.; Haraldsen, I.R.; Torp, R. Elevated mRNA-levels of gonadotropin-releasing hormone and its receptor in plaque-bearing Alzheimer's disease transgenic mice. PLOS ONE 2014, 9, e103607. [CrossRef] [PubMed]

57. Bowen, R.L.; Verdile, G.; Liu, T.; Parlow, A.F.; Perry, G.; Smith, M.A.; Martins, R.N.; Atwood, C.S. Luteinizing hormone, a reproductive regulator that modulates the processing of amyloid-beta precursor protein and amyloid-beta deposition. J. Biol. Chem. 2004, 279, 20539-20545. [CrossRef] [PubMed]

58. Casadesus, G.; Webber, K.M.; Atwood, C.S.; Pappolla, M.A.; Perry, G.; Bowen, R.L.; Smith, M.A. Luteinizing hormone modulates cognition and amyloid-beta deposition in Alzheimer APP transgenic mice. Biochim. Biophys. Acta 2006, 1762, 447-452. [CrossRef] [PubMed]

59. Zhang, G.; Li, J.; Purkayastha, S.; Tang, Y.; Zhang, H.; Yin, Y.; Li, B.; Liu, G.; Cai, D. Hypothalamic programming of systemic ageing involving IKK-beta, NF-kappaB and GnRH. Nature 2013, 497, 211-216. [CrossRef] [PubMed]

60. Falleti, M.G.; Maruff, P.; Burman, P.; Harris, A. The effects of growth hormone (GH) deficiency and GH replacement on cognitive performance in adults: A meta-analysis of the current literature. Psychoneuroendocrinology 2006, 31, 681-691. [CrossRef] [PubMed]

61. Nieves-Martinez, E.; Sonntag, W.E.; Wilson, A.; Donahue, A.; Molina, D.P.; Brunso-Bechtold, J.; Nicolle, M.M. Early-onset GH deficiency results in spatial memory impairment in mid-life and is prevented by GH supplementation. J. Endocrinol. 2010, 20, 31-36. [CrossRef] [PubMed]

62. Moreau, O.K.; Cortet-Rudelli, C.; Yollin, E.; Merlen, E.; Daveluy, W.; Rousseaux, M. Growth hormone replacement therapy in patients with traumatic brain injury. J. Neurotrauma 2013, 30, 998-1006. [CrossRef] [PubMed] 